Editorial

\title{
Do New Technologies in Cardiac Critical Care Add to Social and Economic Challenges in India? A Reality Check
}

\author{
Poonam Malhotra Kapoor ${ }^{1}$ \\ 1Department of Cardiac Anaesthesiology, Cardio Thoracic Centre, \\ All India Institute of Medical Sciences (AlIMS), New Delhi, India
}

J Card Crit Care TSS 2018;2:51-53

In the past 40 years, the epicenter of medicine has moved from the physician to the patient. This has reduced the status of the physician to that of a specialized technician, who, in the eye of the patient, cannot make any mistakes! This is aided by enormous correct or incorrect information that the patient receives from the Internet. The result is that the patient relies more on the Internet and less on the physician. The latter has moved from $2 \%$ in the early 18 th century to $73 \%$ in 2018 .

Cardiac critical care has grown by leaps and bounds in recent years. Growth is never without resistance to provide much needed care in the intensive care units (ICUs). The simulated ICU of the future will have adapted to several edge technologies to constantly reduce the need for human intervention (-Figs. 1, 2). ${ }^{1}$ With advanced medical devices, other support systems that redefine the existing operational ecosystem will come to the forefront. The cost of ICU stay will increase despite the atmosphere becoming more hassle-free.

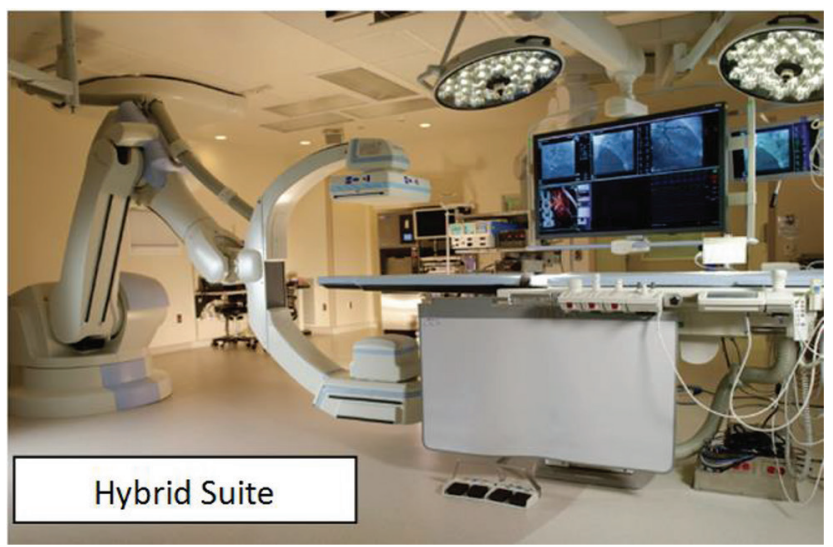

Fig. 1 Hybrid OT in 2019 in Texas, with 4D robotics-all full of recent technology.

Address for correspondence

Poonam Malhotra Kapoor, MD, DNB, MNAMS, FIACTA (Hony), FTEE (Hony), FISCU (Hony), Professor, Department of Cardiac Anaesthesiology, Cardio Thoracic Centre, All India Institute of Medical Sciences (AlIMS),

New Delhi 110029, India

(e-mail: drpoonamaiims@gmail.com).

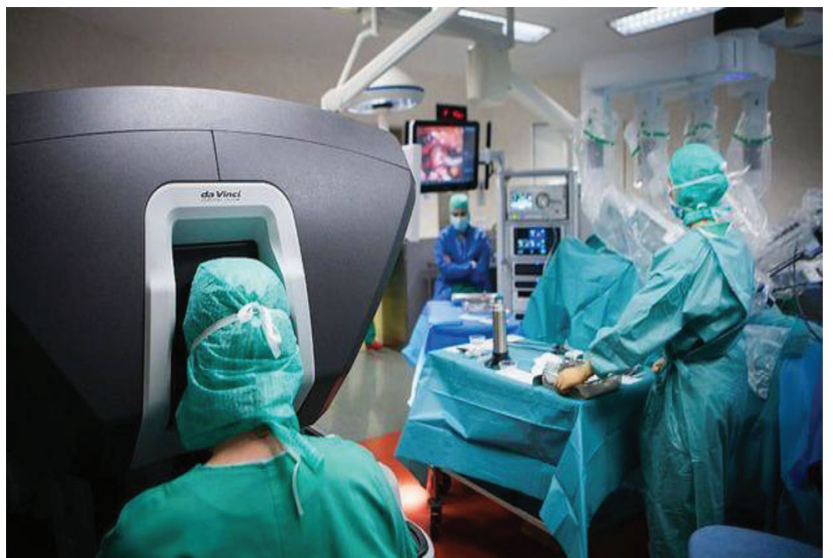

Fig. 2 The robots with the physician doing work 3D behind the console.

\section{Bed Occupancy in Indian Intensive Care Units: Training Intensivists Is the Present- Future Need}

In an overpopulated country such as India, nearly 1.35 billion beds are occupied in the ICU and wards. With nearly 5 million patients overall, there are nearly 70,000 ICU beds available in all big hospitals and small nursing homes in India. This increases the burden of increasing the skills of intensivists. Cardiac critical care in India has entered its youthful stages. Various medical associations such as the Indian Society of Critical Care Medicine (ISCCM), The Simulation Society (TSS), Critical Care Nursing Society, etc. are academically empowering medical personnel to enhance their critical care knowledge and skills to have in Indian ICUs well-trained personnel. Fellowship in cardiac critical care (FICCC) from the TSS is the first of its kind online course in its third year ending with a good accreditation.

Copyright $@ 2018$ Official Publication of The Simulation Society (TSS), accredited by International Society of Cardiovascular Ultrasound (ISCU).

\section{License terms \\ (1) (1) $\Theta \circledast$}


According to the World Economic Forum's insight report, the future of the fast growth consumer market comes with a broad-based pattern of growth and benefit sharing. ${ }^{2}$ This system also breeds in corruption in the health care system, where many persons benefit but not the patient. The result is rise in medical litigation to the physicians and hospitals by the patient party who had previously looked upon the "doctor as a form of God." The boom in the health care industry has led to corruption and malpractices, and nobility of some great physicians remains unveiled.

\section{Technology Effects Ethics}

Life expectancy is affected by climate changes and diseases. Today, with increased life expectancy, patients lead a longer life. Older patients are on a rise. With technology and life expectancy increasing alarmingly, there is an era of robotics, nanotechnology, biotechnology, artificial intelligence (AI), and advanced imaging. We work in a 3D and 4D environment, and with this imaging and navigation, there is no room for any mistakes. Nanotechnology medications are being delivered through the microvasculature today. Change in the lifestyle with technology will lead to better health and an aging population.

Technology affects ethics. There will be no equity left between citizens and countries. This will have a modern social impact wherein there will be a burden on the government for financing larger number of retired people, with emerging personification in living. There will be the pitching of future generations before the retired population. Will they sustain the responsibility and rise to the challenge? This time alone will tell, and there is a new paradigm shift in society.

\section{Rise in Ala Carte System of Medicine}

With greater development in the market such as robotics, positron emission tomography (PET) scans, percutaneous valves in hybrid OTs, etc., there will be a financial crunch leading to "ala carte medicine." Population is large, so training schools and technology should be funded by the citizens of the country, integrating it with the government as a private-public venture. It is up to physicians to rise to this problem by knocking the doors of the government to make new technology available with less cost. They either adopt or reject this growing technology with its cost. Administrators of big and small hospitals have a wider challenge.

\section{Telemedicine-Based Monitoring Electronic Intensive Care Units: Indian Scenario: Intense, Costly Environment}

Electronic ICUs (e-ICUs) or "tele-ICU" are being established across major centers, to optimize health care delivery with better outcomes. Intra-city health care is now achievable with these ICUs. ${ }^{3}$ ICU is today with endless alarms, time-saving sensors technology benefits, and Apps to search immense data, an intense environment to work in. Though it provides great opportunities of employment and jobs, in an ever-changing environment with increasing gadgetry and personnel, it is a costly affair to handle for hospital administrators. With the rising cost in ICU setup-rising to nearly Rs. 1,030 billion in health care in 2012, which will grow to Rs. 2,830 billion by 2021-India is at a tipping point both in terms of economic growth and in the human development of its more than 1 billion citizens. India is the sixth largest economy in the world with its gross domestic product (GDP) at $\$ 2.6$ trillion in 2017. With the 2019 GDP growth rate being projected to nearly $7.5 \%$, India continues to be a major engine of global economic growth. ${ }^{4}$

\section{Growth of Artificial Intelligence Research in India: Boon or Bane?}

The world today is thinking hybrid. With AI, robotics, and nanotechnology, we are as intensivists stepping into the age of machine learning. With university training of AI now available in India (University of Hyderabad, Jadavpur University and Birla Institute of Technology and Sciences leading this field), understanding $\mathrm{AI}$ is becoming robust and easier for the yen generation. Dr. Diwakar Vaish from the A-SET Training and Research Institute, Noida, UP, and the discovery of his wheelchair for handicapped, based on the principle of $\mathrm{AI}$, which is 10 times cheaper than others in its field ( - Fig. $\mathbf{3}$ ), has put India's position as a pioneer in AI with others in the west. As other researchers come up from India, the cost of technology may decrease. Thinking machines can aid the handicapped today, by the invention of a robotic wheelchair by Dr. Vaish. It is 10 times cheaper and AI will be a boon or bane to social economy living. Only the time will tell in the near future; till then technology alone will decide.

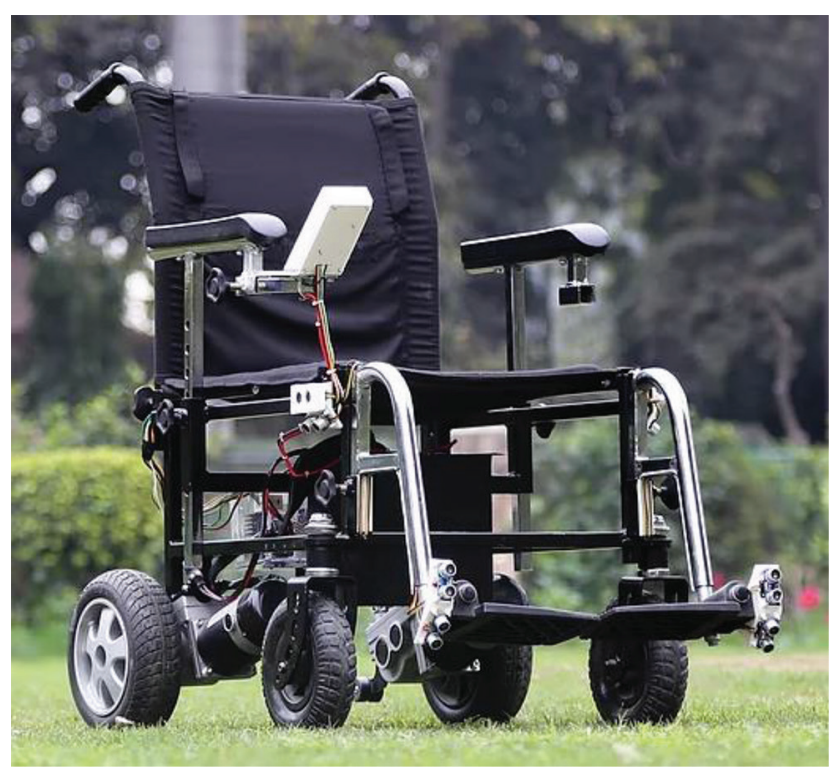

Fig. 3 Artificial intelligence-controlled wheelchair for handicapped patients, improving healthcare in India. 


\section{Conclusion}

Artificial intelligence is the talk of the hour. ${ }^{5}$ There is an economic impact of growing technology on society. Whether technologies such as robotics, nanotechnologies, percutaneous valve implantations, and all costly equipment can be adopted for the "patient in India" time alone will decide. Till then, we need to learn about this expanding filed of novel technologies in cardiac critical care. With further research from India, itself, we may be able to make the ICU more cost-effective.

\section{Conflict of Interest}

None declared.

\section{References}

1 Kaneko T, Davidson MJ. Use of the hybrid operating room in cardiovascular medicine. Circulation 2014;130(11):910-917

2 Udeh C, Udeh B, Rahman N, Canfield C, Campbell J, Hata JS. Telemedicine/Virtual ICU: Where are we and where are we going? Methodist DeBakey Cardiovasc J 2018;14(2):126-133

3 Mohammed H, Hassan MS. How technology will change intensive care unit practice in hospitals. IOSR-JNHS 2018; 7(1):31-34

4 Jayaram R, Ramakrishnan N. Cost of intensive care in India. Indian J Crit Care Med 2008;12(2):55-61

5 Gupta BM, Dhawan SM. Artificial intelligence research in India: a Scientometric Assessment of Publications Output during 2007-16. DESIDOC Journal of Library \& Information Technology 2018;38(6):416-422 